the Scottish Green Paper, which was written after consultation with the professions and other interested bodies, makes it clear that no support could be found for putting health services under local authority control and that alternative proposals would be considered. A total of 40-50 boards is too small for some purposes and too large for others. Experience with regional hospital boards has shown that if professional staff of high calibre are to be recruited-and this means architects, engineers, and so on as well as doctors-the area and population covered must be large enough for the job to be worth while; and only large authorities can afford and justify rates of pay good enough to attract really good staff. On the other hand, if the boards are to have any real contact with local communities and their interests then 40-50 is far too few for England and Wales. So once the proposed marriage between area boards and local authorities is broken off the answer seems clear: about 15-20 area boards and a larger number of district boards concerned with local matters. Again the Scottish Green Paper repays study. Despite its apparent rejection of the two-tier structure it proposed that local committees might be appointed in those areas which are remote from the boards. Since the proposed Scottish boards are in any case smaller than the English ones the case for the two-tier system for England and Wales is most persuasive.

The area boards proposed in the English Green Paper would achieve a "clean break" with the present system by having no committees set up to look after sectional interests, such as general-practitioner services; all standing committees would cover all parts of the service. Comment in the Green Papers makes it clear that the Government believes that integration depends for its success on the eradication of any traces of the present tripartite system. The departments suggested for the area boards are for planning, staffing, logistics, and finance, and a secretariat. This scheme is in strong contrast to the Porritt Report's subsidiary councils, and the B.M.A. Council wants each area board to have councils of this kind with elected representatives of the branch of the profession concerned. Indeed, the G.M.S. Committee suggests that area boards should be concerned with planning and evaluation and that administration and finance should still be organized on the tripartite system. Representatives of each branch of the profession have natural anxieties about its future when major changes are made. Administrative efficiency and democratic representation are antipathetic, and an acceptable compromise will have to be found.

So changes will be needed in the Green Paper proposais before they are acceptable to the profession. But the other side of the picture also needs emphasis. Reform of the N.H.S. gives opportunities for introducing many of the changes that doctors agree are needed to put life back into the Service. For instance, staffing structure proposed for the hospital service last week (p. 720) should make for closer co-operation between G.P.s and their hospital colleagues, and should lead to the breaking down of some of the barriers. And there will be other ways of increasing functional integration irrespective of administrative reform.

The profession should insist on proper occupational and community health services in the new system. The relationship of the teaching hospitals and universities to the boards needs further study; teaching and research must not

1 The Administrative Structure of the Medical and Related Services in England and Wales, 1968. H.M.S.O.

Administrative Reorganization of the Scottish Health Service, 1968. H.M.S.O.

- A Review of the Medical Services in Great Britain, 1962. London. be subordinated to service needs just for administrative convenience.

Changes in medicine are unpredictable, and it is essential that the new structure is flexible enough to cope with these. Each area board should be given scope to design its services to suit the needs of the area. The Health Departments should give enough financial and administrative control to the boards to allow them to be imaginative and creative, which is impossible with rigid annual budgeting. Adequate finance is essential, yet some features of the proposals in the Green Paper can be interpreted only as offering the cheapest solution. But above all the Government must be left in no doubt that the development of the medical services will be seriously impaired if the influence of the medical profession on the course of events is in any way weakened.

\section{Infected Chicken}

A well-documented account of an outbreak of infectious disease identified, traced to its source, and brought under control is not only instructive to those concerned even in only a limited way with public health but also possesses something of the entertainment value of a well-plotted detective story. The reports by Professor A. B. Semple, Dr. G. C. Turner, and Dr. D. M. O. Lowry at page 801 and by Dr. J. H. Pennington and his colleagues at page 804 of the B.M.f. this week on an outbreak of infection due to Salmonella virchow in man, cattle, and poultry in the north-west of England are models of the way in which such investigations should be made. They also testify to the fruitful results to which collaboration between the medical and veterinary services can lead.

The public health authority in Liverpool was first warned by a general practitioner of a possible outbreak of foodpoisoning within less than four days of the last mouthful of infected chicken being swallowed at a communal meal. It is to this alert and anonymous family doctor that at least some of the credit for the subsequent exposure of an unsavoury hygienic situation should go. Fifty out of 120 people who had eaten cold spit-roasted chicken at the meal had symptoms of food-poisoning and were found to be excreting $S$. virchow. In the course of the inquiry it emerged that no fewer than 162 people in the Merseyside conurbation were or had been excreters of $S$. virchow during the 11 weeks which extended from two weeks before the meal which gave rise to the outbreak to nearly nine weeks after it. $S$. virchow is not a common cause of human food-poisoning, as the statistics for the Liverpool area for the period before the reported outbreak suggest. Possibly partly because of this the clinical picture was severe, and just over $20 \%$ of the patients required admission to hospital for periods of more than a week. $S$. virchow was isolated from blood cultures in eight of the patients. Semple and his colleagues were disturbed by the number of patients who remained excreters of the germ after clinical recovery. R. C. S. Burnett and B. I. Davies ${ }^{1}$ reported prolonged excretion of Salmonella reading in connexion with an outbreak due to that germ. In another episode M. Lennox

1 Burnett, R. C. S., and Davies, B. I., f. Hyg. (Lond.), 1967, 65, 1.

2 Lennox, M., Harvey, R W. S., and Thomson, S., f. Hyg. (Lond.), 1954, 52, 311. s George, T. C. R., Harvey, R. W. S., and Thomson, S., F. Hyg. (Lond.).
1953, 5i, 532 . 
and his colleagues ${ }^{2}$ found that one of their patients continued to excrete Salmonella typhimurium for 17 weeks from the time of getting the infection. They calculated that the decline in the population of excreters followed almost exactly the pattern which had been reported previously in an outbreak of infection with Salmonella paratyphi-B described by T. C. R. George, R. W. S. Harvey, and S. Thomson. ${ }^{3}$ The data presented by Semple and his colleagues are not in such a form as to permit comparison with those reported by these other workers, but it would be worth knowing whether the decline in the number of excreters after an outbreak of salmonellosis follows a recognizable and predictable pattern.

The outbreak of human food-poisoning prompted bacteriological investigations into the packing station and 14 chickenrearing farms in Cheshire from which the poultry which had caused the outbreak were supplied. J. H. Pennington and his colleagues report at page 804 that $S$. virchow was isolated in nine farms, the packing station, and the hatchery, while several of the workers on the farms were infected. Cattle grazing on land manured with litter from two of the farms, one of which was infected, themselves became infected with $S$. virchow.

One of the factors responsible for disseminating the infection even more widely to other foodstuffs was poor hygiene in the kitchen of the premises in which the chicken was prepared. It is clear from the account given by Semple and his colleagues that the working place was inadequate and the preparation of the food unhygienic. Moreover, the infected chicken had been deep-frozen and was spit-roasted after a very brief thawing period, so that it is unlikely that the cooking can have raised the temperature of the carcasses high enough to have significantly reduced the population of the pathogens in and on them. All too often food is prepared in catering establishments in Britain under thoroughly unsuitable conditions. It is not at all easy to understand why the public health authorities seem so reluctant to use the formidable powers devolved upon them by the Ministry of Agriculture and the Department of Health and Social Security. Under the Food and Drugs Act, 1955, they can insist on a hygienic environment and a healthy work force in the catering industry. After all, to keep the lid of Pandora's box firmly closed is the true purpose of preventive medicine.

\section{International Co-operation}

In the last few years substantial technical developments have been made in the control of tropical disease. Mass campaigns and new methods have restricted the extent of yaws, poliomyelitis, tuberculosis, and yellow fever. Malaria eradication programmes have been successful over wide areas. Advances have been made in chemotherapy and chemoprophylaxis, and new or better vaccines have been produced.

Despite these developments, however, there is still the threat of widespread outbreaks of some of the quarantinable diseases. For example, cholera el Tor $^{12}$ has recently spread from Sukuwesi (Celebes) to New Guinea, the Philippines, China, Hong Kong, Thailand, Southern Russia, Iran, and Iraq. At p. 789 of this week's B.M.F. Dr. P. Dorolle, the Deputy Director of the World Health Organization, argues that the existing international sanitary regulations are inadequate. Some countries have introduced exaggerated precautions much in excess of those prescribed by the inter- national regulations. Others have deliberately failed to notify an outbreak because of the fear of excessive reactions from other countries. Moreover, the current regulations have failed in other ways, notably in preventing the introduction of smallpox into non-epidemic countries. Dr. Dorolle concludes that the regulations can work only when they are properly applied in a co-operative effort. They have failed from lack of accurate reporting, failure of detection, and difficulty of enforcement.

Clearly, therefore, in an age of great and increasing speed of travel and increasing numbers of international travellers the old regulations are inadequate. This situation was discussed at a conference on international co-operation held in 1967 by W.H.O. An important outcome of this and other discussions on the quarantinable diseases was the demand for a complete review of the international sanitary regulations. This was recommended at the 21st World Health Assembly in May this year, and, in keeping with this proposal, W.H.O. has merged its old division of International Quarantine with that of Global Epidemiological Surveillance.

Hence the regulations should soon be given a new and modern look, but until then they will have to be enforcedwe hope with more understanding. In the past they have been negative and compulsive, and have been carried out with a "legalistic and regulation-minded" attitude. Dr. Dorolle voices the views of the vast majority of those who work in this field when he hopes that this rigid philosophy will give way nationally and internationally to a more scientific and technical approach. The latter should be based on the introduction of epidemiological surveillance, amounting to continuous scrutiny of the distribution and spread of communicable diseases, the prediction of the development of potentially serious situations, and the collection of data of sufficient accuracy and completeness to serve as a basis for effective control.

What can be done in this field has been shown by the growth of the international surveillance of influenza, which is not one of the "quarantinable" diseases, though from time to time it causes world pandemics. A World Influenza Centre was established in the Medical Research Council Laboratories in London in 1947 ; today there are over 50 countries collaboratin. $n$ a world programme, collecting and distributing information on the national and global occurrence of the disease and on the details of the viruses concerned and their antigenic structure, with a view to the ultimate production of vaccine. The programme is based on voluntary collaboration on a scientific and professional level with no element of compulsion. It is a good example of the way in which detection and notification of a communicable disease beginning at national level can be extended to co-operative international surveillance.

Such an approach will do much to prevent the spread of disease, but the real solution lies ultimately in eliminating the endemic foci altogether-though the examples of diseases like malaria and smallpox, of which areas of infection persist despite a careful and thorough attack, show how difficult this will be.

With few exceptions, the major diseases concerned are those which originate from countries which are at present underdeveloped and in which the traditional methods of control, such as repeated mass vaccination in smallpox, are too difficult to deploy and the newer surveillance too dependent on technical staff and labour which do not exist. In

\footnotetext{
Brit. med. 7., 1966, 1, 1555.

Wallace, C. K., et al., Brit. med. F., 1966, 2, 447
} 